\title{
PESQUISA EM EDUCAÇÃO AMBIENTAL EM CONTEXTOS NÃO ESCOLARES: PERTINENCIA DO RECORTE E INTERFACES ENTRE OS GRUPOS DE DISCUSSÃO DOS ENCONTROS DE PESQUISA EM EDUCAÇÃO AMBIENTAL (EPEA'S)
}

\author{
Maryane Vieira Saisse ${ }^{1}$ \\ Haydée Torres de Oliveira ${ }^{2}$ \\ Carolina Buso Dornfeld ${ }^{3}$ \\ Anelize Queiroz Amaral ${ }^{4}$
}

\section{Resumo}

O Grupo de Discussão e Pesquisa (GDP) em diferentes abordagens e contextos é uma modalidade instituída, a partir de 2009, nas edições bianuais dos Encontros de Pesquisa em Educação Ambiental (EPEAs), com o objetivo de criar um espaço para o diálogo sobre os acúmulos e desafios da pesquisa em educação ambiental (EA) num determinado recorte. Neste texto estão apresentadas as reflexões em torno da realização do GDP Educação Ambiental em Contextos não escolares, durante o VIII EPEA (2015). As variações ao longo do tempo, em termos de participação, as interfaces e sobreposições com outros GDPs e alguns conceitos e práticas relacionados ao contexto não escolar são apreciados pelas autoras, considerando suas experiências nesse campo.

Palavras-chave: Educação ambiental. Pesquisa. Contexto não escolar.

\section{RESEARCH IN ENVIRONMENTAL EDUCATION IN NON-SCHOOL CONTEXTS: RELEVANCE OF CLIPPING AND INTERFACES BETWEEN THE DISCUSSION GROUPS OF THE RESEARCH MEETINGS ON ENVIRONMENTAL EDUCATION}

\begin{abstract}
The Discussion Group on EE Research Group (DGR) in different approaches and contexts is a modality established from 2009 in the bi-annual editions of the Research Meetings on Environmental Education with the aim of creating a space for dialogue on the accumulation and challenges of research in environmental education (EE) in a given situation. In this text will be presented our reflections on DGR "Environmental Education in non-school Contexts " during the venue of the VIII EPEA (2015). Changes over time in terms of participation, interfaces and overlaps with others DGR and some concepts and practices related to nonschool context are appreciated by the authors, considering their experience in this field.
\end{abstract}

Keywords: Environmental Education. Research. Non-school context.

\footnotetext{
${ }^{1}$ Pesquisadora/educadora do Jardim Botânico do Rio de Janeiro, Rio de Janeiro, Brasil.

2 Professora Sênior do Departamento de Ciências Ambientais - Universidade Federal de São Carlos (UFSCar), São Carlos, São Paulo, Brasil.

${ }^{3}$ Docente da Universidade Estadual Paulista Júlio de Mesquita Filho - (UNESP), Ilha Solteira, São Paulo, Brasil.

${ }^{4}$ Docente da Universidade Tecnológica Federal do Paraná (UTFPR), Dois Vizinhos, Paraná, Brasil.
} 


\title{
INVESTIGACIÓN EN EDUCACIÓN AMBIENTAL EN CONTEXTOS NO ESCOLARES: \\ PERTINENCIA DEL RECORTE Y LAS INTERFACES ENTRE LOS GRUPOS DE DISCUSIÓN DE LOS ENCUENTROS DE INVESTIGACIÓN EN EDUCACIÓN AMBIENTAL
}

\begin{abstract}
Resumen
El Grupo de Discusión e Pesquisa (GDP) en diferentes enfoques y contextos es una modalidad establecida, a partir de 2009, en las ediciones bianuales de los Encuentros de Pesquisa en Educación Ambiental (EPEAs), con el objetivo de crear un espacio para el diálogo sobre los retos de la investigación en educación ambiental (EA) en un recorte determinado. Este texto presenta las reflexiones sobre el logro del GDP Educación Ambiental en contextos no escolares, durante la EPEA VIII (2015). Cambios en el tiempo en términos de participación, las interfaces y superposiciones con otros GDPs y algunos conceptos y prácticas relacionadas con el contexto no escolar son apreciados por las autoras, teniendo en cuenta su experiencia en este campo.
\end{abstract}

Palabras-clave: Educación ambiental. Pesquisa. Contexto no escolar.

\section{Introdução}

O Grupo de Discussão e Pesquisa (GDP) em diferentes abordagens e contextos é uma modalidade instituída, a partir de 2009, nas edições bianuais dos Encontros de Pesquisa em Educação Ambiental (EPEAs), organizados por grupos de pesquisa de diferentes instituições acadêmicas públicas brasileiras, desde 2001. Sua finalidade é estabelecer um fórum de diálogo, agregando as pesquisadoras ${ }^{5}$ e pesquisadores que escolhem subscrever seus trabalhos em um determinado GDP, interessadas/os em compartilhar com seus pares os acúmulos e desafios da pesquisa em educação ambiental (EA) naquele determinado recorte. No presente artigo serão apresentadas as reflexões em torno da realização do GDP Educação Ambiental em Contextos não escolares realizado durante o VIII EPEA, ocorrido entre os dias 19 e 22 de julho de 2015, na cidade do Rio de Janeiro.

O GDP Educação Ambiental em Contextos não escolares foi criado no VI EPEA, ocorrido em Ribeirão Preto (SP) em 2011, quando um grupo de pesquisadores/as iniciou a discussão sobre a EA em diferentes contextos (HIGUCHI; ZATTONI; BUENO, 2012). Naquele momento, as reflexões produzidas no grupo resultaram no entendimento do termo contexto como "um espaço de acontecimento social que não se limita por barreiras físicas, mas por territorialidades fluidas e intencionalidades próprias que transcendem aspectos de lugar. Existe, no entanto, uma dimensão temporal estabelecida como marcação de acontecimentos" (HIGUCHI, ZATTONI; BUENO, 2012, p.120).

A natureza, enquanto um aspecto desse contexto, teve destaque especial nas primeiras discussões, entendida como diversa e questionada por ter sua dimensão, muitas vezes, limitada à paisagem. Provavelmente, pelas próprias características das experiências apresentadas naquele GDP, que tratavam principalmente da relação entre educação formal e educação não formal, termos que serão problematizados mais adiante, em atividades ocorridas em ambientes naturais. Eram exemplos de projetos nascidos em escolas e que buscaram, em parceria com gestores e educadores de áreas protegidas, sensibilizar os/as estudantes em relação à proteção de ambientes naturais; formação em EA com estudantes de turismo em

\footnotetext{
${ }^{5}$ Por opção das autoras, neste texto se adota a chamada linguagem não sexista, não necessariamente em acordo com a norma gramatical vigente.
} 
Unidade de Conservação e uma formação de educadores ao ar livre, baseada na proposta metodológica de educação experiencial, no formato de expedição, e, ainda, um curso de imersão para professores do ensino médio da rede pública, ocorrido na Amazônia.

Podemos observar, assim, que naquele primeiro momento as discussões sobre a especificidade do contexto a ser trabalhado no GDP se fizeram sublinhando a inter-relação entre o formal e o não formal da ação educativa e de certa preponderância da natureza como território para o desenvolvimento dessa relação.

Em 2013, de acordo com os Anais do VII EPEA, verificou-se que a Comissão Organizadora do evento recebeu um total de 162 trabalhos, e, ao final de um rigoroso e cuidadoso processo de avaliação, 101 trabalhos foram aprovados, sendo que desse total 90 trabalhos foram efetivamente apresentados nos Anais do evento (VII EPEA, 2013).

Durante as discussões no GDP, e por meio da análise dos trabalhos apresentados naquele ano (2013), ficou evidenciado que a apropriação das espacialidades além dos muros da escola era ainda um desafio tanto para educadores quanto para a produção de conhecimento científico acerca desses processos educativos e suas implicações (HIGUCHI; MAROTI, 2014). Nesse artigo, os autores levaram em consideração os seis trabalhos apresentados no GDP e revistos para publicação, o que de alguma forma sinaliza para uma situação pouco representativa do que tem sido produzido em termos de pesquisas em contextos não escolares da EA.

Em 2015, no VIII Encontro Pesquisa em Educação Ambiental, foram configurados oito GDPs. O GDP Educação Ambiental em Contextos não escolares está entre um dos GDPs com menor número de trabalhos inscritos, junto aos GDP's Educação Ambiental e Culturas e Educação Ambiental e Questões Metodológicas, todos com 20 trabalhos, de um total de 115 trabalhos aprovados para apresentação no evento. Dos vinte trabalhos inscritos no GDP Educação Ambiental em Contextos não escolares, apenas sete foram aprovados, configurando-se como um dos GDPs com menor número de trabalhos aceitos e, principalmente, apresentados. Dos sete trabalhos aceitos no VIII EPEA, quatro tratavam de pesquisas realizadas por pesquisadores/as brasileiros/as, dois trabalhos foram realizados na Colômbia e um na Argentina. Porém, nenhum/a desses/as autoras/es esteve presente nos momentos de encontro do GDP, o que se configurou como uma dificuldade na construção de reflexões entre o grupo e um maior aprofundamento dos trabalhos aprovados, como era a expectativa do comitê organizador. Não podemos afirmar se as/os autoras/es estiveram presentes nas sessões orais e, por algum motivo, priorizaram os debates em outros GDPs, portanto, as discussões foram conduzidas com participantes do VIII EPEA, que se inscreveram intencionalmente nesse GDP e que tem ou tiveram experiência em pesquisa e projetos de EA em contextos não escolares, mas que, no entanto, neste evento não estavam apresentando resultados de pesquisa. Nos Anais do Evento ${ }^{6}$, consta a publicação de seis desses trabalhos, indicando que um deles não foi apresentado.

A quantidade de trabalhos, relativamente baixa, de pesquisas inscritas e apresentadas em 2015, não ilustra uma situação pontual, mas que pode ser observada desde o VI EPEA, em 2011, quando o GDP Educação Ambiental em Contextos não escolares foi criado. Naquela ocasião foram 12 os trabalhos apresentados, seguidos de 6 trabalhos no ano de 2013.

Enfoca-se, aqui, a necessidade e o comprometimento das/os pesquisadoras/es do campo se fazerem presentes em momentos como esse, de grande aprendizado e troca de experiências entre o grupo de pesquisadoras/es, e, ao mesmo tempo, nos leva a pensar na necessidade de repensar o formato do evento. Esse quadro aponta algumas questões que precisam ser pensadas e alguns problemas enfrentados para melhor contribuição do GDP no

\footnotetext{
${ }^{6}$ Disponível em: <http://epea.tmp.br/epea2015_anais/plenary/>.
} 
diálogo entre as pesquisas que acontecem fora do contexto escolar e ao campo da pesquisa em EA como um todo.

Portanto, mesmo salientando que as questões seriam mais enriquecedoras se os autores dos trabalhos aprovados tivessem participado das discussões no GDP, trazendo suas experiências e diálogos para esse debate que se faz único no campo da Pesquisa em EA, nossa reflexão nos encontros realizados se deu no sentido de contribuir para os pensares que estão sendo construídos acerca da identidade da EA em contextos não escolares e sobre suas especificidades, e a necessidade de um GDP que se debruce sobre esse contexto.

Tomamos como ponto de partida nossa leitura prévia do conjunto dos trabalhos aprovados, observando que se tratavam de diversos contextos:

- $\quad$ Bairros/comunidades (viveiros de espécies nativas)

- $\quad$ Organizações não-governamentais

- Licenciamento ambiental

- $\quad$ Gestão de Riscos Ecológicos

- $\quad$ Empresas

- $\quad$ Gestão Ambiental Pública

Embora a EA, no Brasil, tenha se desenvolvido inicialmente no âmbito das organizações não governamentais (ONGs), e em seguida por órgãos governamentais, especialmente em áreas protegidas (unidades de conservação) e, posteriormente, nas escolas, é fato que as fronteiras entre esses diferentes espaços e os muros das escolas já não são claros. Ao que nos parece, trazem um elemento de complexidade para os recortes que foram estabelecidos nos GDPs, discutidos adiante. Não há dúvida, por outro lado, de que essa diversidade representa a possibilidade de envolvimento de públicos diferenciados, cujos olhares e vozes podem contribuir com questões relacionadas à temática ambiental.

Diversos são os novos marcos fronteiriços em que a EA vêm ocorrendo, porém, devese atentar para os riscos que tal abrangência pode gerar, como fragilidades teóricometodológicas, ausência de debates e participação da comunidade, intencionalidades lucrativas e até mesmo alienação via a lógica mercadológica, dependendo de quem a está ofertando. Corroborando, ao analisar os artigos aprovados observamos, também, quais os sujeitos que estão sendo privilegiados nessas discussões, sendo que dentre eles estão:

- $\quad$ Agentes de Organizações Não Governamentais

- $\quad$ Comunidade local

- $\quad$ Profissionais formuladores de material educativo

- $\quad$ Agentes envolvidos em projetos de Licenciamento Ambiental

- Trabalhadores de Microempresas

- $\quad$ Moradores de Condomínio (município de Niterói)

Há uma interessante abordagem sobre esse aspecto característico do campo da EA sua diversidade - no livro "Os diferentes matizes da EA no Brasil - 1997 - 2007", em que é apontada a importância de se reconhecer essa abrangência e a pretensa ideia de consenso entre as diferentes vertentes e abordagens da EA (BRASIL, 2008). Fica evidente, assim, a necessidade de discussões e encontros proporcionados por espaços de diálogo como os GDPs para que possamos tornar as reflexões e, posteriormente, as ações cada vez mais enriquecedoras do ponto de vista teórico-metodológico, para que não sejamos alvos de armadilhas que resultem em ações utilitaristas, pontuais e pragmáticas.

Dentre os objetivos das pesquisas observadas, estão: sensibilizar para riscos, relacionar tipos de financiamento e qualidade da ação educativa, refletir sobre a relação entre conflitos, justiça e conservação ambiental, analisar material educativo, relacionar ações educativas relacionadas ao licenciamento com princípios da PNEA, avaliação de projetos de coleta seletiva de lixo, analisar capacitação de trabalhadores de microempresa para otimização do uso dos recursos naturais. 
Para a realização das pesquisas apontadas, observou-se que as metodologias utilizadas se enquadraram nas modalidades Estudo de Caso e Pesquisa Participante. As/os autoras/es mencionam, como instrumentos de coleta de dados, o diagnóstico socioambiental, entrevistas semiestruturadas (individual e em grupo), observação, questionário, análise documental e revisão da literatura. $\mathrm{E}$, como procedimentos metodológicos de análise, foram mencionadas a análise de conteúdo e a análise do discurso.

Foram observados, também, os referenciais teóricos que estão sendo utilizados para o embasamento teórico de pesquisas desenvolvidas em contextos não escolares. Dentre as autoras e autores citados, destacam-se Edgar González-Gaudiano, Philipe P. Layrargues, Gustavo Lima, Marilia Tozoni-Reis, Allier, Enrique Leff, Carlos Frederico Loureiro, Pedro Jacobi, Ulrick Beck, Isabel Carvalho, José Silva Quintas, Mauro Guimarães, Monica Serrão, Leonardo Boff, Alexandre de Gusmão Pedrini e André Trigueiro.

Dentre os resultados dessas pesquisas, podemos destacar que:

1) Foram evidenciadas as dificuldades que as ONGs ambientalistas do Estado de São Paulo enfrentam para poder atuar, manter-se e expandir suas ações ao longo do tempo, e que as maiores fontes de financiamento das mesmas são órgãos públicos e as empresas privadas, mas considera-se, também, que ainda é relevante a captação de recursos de forma voluntária através de doações de pessoas físicas e atividades beneficentes. Além disso, pelo relato dos entrevistados foi possível verificar que não há uma maior influência de empresas privadas nas ações realizadas por essas ONGs. Porém, um fato preocupante, que foi ressaltado no trabalho, é que há uma tendência dessas ONGs em terem uma atuação ativista e com pouca fundamentação teórica (FOSSALUZA; TOZONI-REIS, 2015). São questões relevantes acerca do financiamento privado de projetos de EA realizados por ONGs, no que diz respeito à sua interferência no desenvolvimento das ações implementadas. Muitas vezes, mais do que meras fornecedoras de materiais didáticos e ações pontuais, as iniciativas privadas passam a incidir sobre a política local e sobre o desenvolvimento do trabalho, com o risco de afetar a autonomia da proposta original.

2) A tarefa de sensibilização e comunicação foi uma instância prévia e paralela dos processos de EA nos viveiros para que o Estado Provincial (da Patagônia Argentina) incorpore a gestão ambiental à legislação da restauração mediante utilização de espécies nativas. Os autores também observaram que, quando não existe apoio econômico para infraestrutura e subsídios, o viveiro não pode se sustentar sozinho. Um aspecto positivo apontado no trabalho foi que cada viveiro constituiu uma comunidade de prática. Havia uma interação de todos os participantes com profissionais qualificadas/os (especialistas), mas o aspecto mais importante foi que foram cumpridos os pressupostos de trabalho em um tipo de comunidade que se configurava como um empreendimento conjunto, continuamente renegociada por seus membros e que devia funcionar com o compromisso mútuo de seus membros que se uniram e conseguiram um repertório compartilhado de recursos comuns que os membros foram desenvolvendo com o tempo (PÉREZ; MEINARDI, 2015).

3) Pela análise documental de publicações da imprensa da região do Pance (Colômbia), as autoras mencionam que durante períodos 1980-2014, a comunidade e as/os visitantes não foram suficientemente empoderados, não se apropriando de seu território, e que é dado destaque para o Parque Nacional Los Farallones, a sub-bacia da jurisprudência de Pance como locais de recreação e educação. A proposta de EA foi intitulada de Paisagem e envolvimento da comunidade: uma proposta educativa em busca da valoração da paisagem a Justiça Ambiental e baseava-se na organização de grupos de trabalho desde uma instituição educativa, tomando a escola como elo articulador entre a/o estudante e sua comunidade, propiciando que as/os estudantes pudessem reencontrar valores ancestrais para compreender o valor e as mudanças geradas, e sentir-se como agentes de transformação contínua dessas paisagens como parte de seu território (ORJUELA; MEJÍA, 2015). 
4) As ações de EA promovidas pelo órgão responsável pela Coleta Seletiva foram pontuais e isoladas e não houve articulação com o programa de coleta seletiva municipal. Com a aplicação dos questionários, verificou-se que as/os moradoras/es demonstram um despreparo e uma lacuna de conhecimento diante dos impactos ambientais causados pelos resíduos produzidos em sua residência (QUEIROZ, 2015).

5) No material didático analisado, sobre Gestão de Riscos Geológico-Geotécnicos, houve ocorrência preponderante de conteúdos cientificistas e comportamentalistas, que não geram um questionamento sobre os cenários de riscos, segundo suas/seus autoras/es. Além disso, foi possível verificar uma tendência no material da vertente da EA pragmática e que as ações são limitadas a certos períodos do ano e, consequentemente, esse conhecer torna-se momentâneo e exclusivo para atuar num período. Nesse sentido, sugere-se que seja feito um trabalho contínuo, durante um ano, que possa ir além de estabelecer o comportamento e a prevenção de riscos (LIERS; PAIVA; SILVA, 2015).

6) $\mathrm{O}$ maior problema identificado na microempresa colombiana de reciclagem foi a falta de limpeza em todas as áreas, ocasionando um aspecto ruim e riscos biológicos para a saúde dos trabalhadores. Mais de $80 \%$ das pessoas entrevistadas disseram ter recebido algum tipo de capacitação por parte da empresa sobre temas relacionados aos cuidados com o meio ambiente. A capacitação não foi realizada, apenas foi elaborada a proposta (ALEGRÍA; RODAS; CÁCERES, 2015).

7) Por parte das consultorias ainda existe um entendimento de que EA é igual a treinamento e que também há falta de profissionais qualificados para sua implementação. Ainda, há uma compreensão limitada sobre o PEAT (Programa de Educação Ambiental dos Trabalhadores, cf. Instrução Normativa IBAMA 02/2012) pelos empreendedores, que também identificam a dificuldade de implementação da EA em virtude da dinâmica operacional da empresa. Em relação ao IBAMA (Instituto Brasileiro do Meio Ambiente e dos Recursos Naturais Renováveis), observou-se a questão de uma concepção maniqueísta, a falta de diálogo com os consultores e a falta de funcionários na instituição. Sendo assim, as/os autoras/es apontam uma deficiência (por parte das consultorias) em incorporar os fundamentos teóricos da EA ao PEAT submetido para aprovação do órgão ambiental licenciador; inadequação das concepções metodológicas do PEAT, com consequentes advertências por parte do órgão ambiental e o engendramento de uma situação de incoerência na qual o órgão ambiental licenciador aprova um documento escrito (PEAT submetido) e desaprova as práticas educativas por este desencadeadas (PEIXOTO; MATTOS; CATALDO, 2015).

\section{Problematizando alguns conceitos}

Um dos termos recorrentes quando falamos de contextos escolares e não escolares é a designação educação formal e educação não formal.

Segundo Gohn (2006, p.28) a educação formal é aquela desenvolvida nas escolas, com conteúdos previamente demarcados; a informal é aquela que os indivíduos aprendem durante seu processo de socialização - na família, bairro, clube, amigos etc., carregada de valores e culturas próprios, de pertencimento e sentimentos herdados; a educação não formal, por sua vez, é aquela que se aprende "no mundo da vida", via processos de compartilhamento de experiências, principalmente em espaços coletivos e ações cotidianas. Assim, consideramos que, diferentemente da educação informal, a educação não formal apresenta-se de forma sistematizada e intencional.

Considerando essa definição, compartilhada por diferentes educadoras e educadores (HIGUCHI; ZATTONI; BUENO, 2012), entendemos que referir-nos à educação formal como educação escolar ou escolarizada seria pertinente. Da mesma maneira, a EA em espaços 
outros que não a escola, pode ser nominada como EA não escolar. Daí a escolha pelo recorte do GDP a que nos referimos neste trabalho, ou seja, EA em contextos não escolares. Gohn (2014, p. 38) ainda acrescenta que na educação não formal "o contexto tem um papel de alta relevância porque ele é o cenário, o território de pertencimento dos indivíduos e grupos envolvidos".

Em relação aos espaços onde as atividades da educação não formal ocorreriam, Gohn (2006, p. 29) referem-se a espaços educativos que "localizam-se em territórios que acompanham as trajetórias de vida dos grupos e indivíduos, fora das escolas, em locais informais, locais onde há processos interativos intencionais (a questão da intencionalidade é um elemento importante de diferenciação)".

Nessa linha, poderíamos trazer o conceito de espaços educadores, que vem sendo desenvolvido no campo da EA, conforme apontam Oliveira et al. (2016). Para Matarezi (2005, p. 164) um espaço dessa natureza deve possuir "características educadoras e emancipatórias, que contenham em si o potencial de provocar descobertas e reflexões, individuais e coletivas simultaneamente, a exemplo do poder provocador e até transformador de uma obra de arte", ou, em outras palavras, que tenha a referida intencionalidade.

Para Kunieda (2010) o termo espaço educador é uma metáfora utilizada para ressaltar o protagonismo do espaço e de suas estruturas no processo educativo, funcionando como um agente ativo e não apenas como um cenário onde o ensino e a aprendizagem ocorrem. Seria, portanto, um espaço simbólico e vivencial, no qual a experiência pessoal vivenciada com cada espaço ganha relevância na aprendizagem. Adicionalmente, temos, segundo Jacobucci (2008) que o uso do termo espaço não formal tem sido utilizado para descrever lugares, diferentes da escola, onde é possível realizar atividades educativas. Segundo essa autora, existem duas categorias que podem ser sugeridas de espaços não formais, quais sejam: locais que são instituições e locais que não são institucionalizados:

Na categoria Instituições, podem ser incluídos os espaços que são regulamentados e que possuem equipe técnica responsável pelas atividades executadas, sendo o caso dos Museus, Centros de Ciências, Parques Ecológicos, Parques Zoobotânicos, Jardins Botânicos, Planetários, Institutos de Pesquisa, Aquários, Zoológicos, dentre outros. Já os ambientes naturais ou urbanos que não dispõem de estruturação institucional, mas onde é possível adotar práticas educativas, englobam a categoria Não-Instituições. Nessa categoria podem ser incluídos teatro, parque, casa, rua, praça, terreno, cinema, praia, caverna, rio, lagoa, campo de futebol, dentre outros inúmeros espaços (JACOBUCCI, 2008, p. 56-57).

Considerando a amplitude de espaços, públicos e temáticas que a conceituação contextos não escolares permite, pode-se enunciar a pertinência ou não desse recorte, bem como sua sobreposição em relação a outros GDPs, como o GDP Pesquisa em EA e Culturas e Pesquisa em EA e Movimentos Sociais ou Pesquisa em EA e Políticas Públicas.

\section{Reflexões sobre o contexto e a identidade dos trabalhos que se vinculam ao GDP Educação Ambiental em contextos não escolares}

No campo da EA não são novidade os debates sobre o que constitui o contexto não escolar, isto é, a educação não formal. Nas décadas de 1960-70, percebeu-se, claramente, a penetração desses questionamentos nos setores mais diversos da sociedade contemporânea (CARVALHO, 2000). A emergência do ambientalismo, que se une às lutas pelas liberdades democráticas, manifesta-se por meio de ações isoladas de organizações da sociedade civil e mesmo de prefeituras e governos estaduais e federais, sendo a abordagem marcada por características conservacionistas. 
Para Brügger (1994), nessa ótica do conservacionismo a problemática ambiental é vista, exclusivamente, por dimensões naturais e técnicas, negligenciando as dimensões sociais e políticas. Essa perspectiva de EA é denominada pela autora como adestramento ambiental, caracterizada pela falta de diálogos, numa perspectiva reducionista, fragmentada, individualista e exclusivamente de ordem comportamentalista.

Por ter sido muito impulsionada e, primeiramente, legitimada nas políticas ambientais, essa dimensão educativa se desenvolve principalmente fora da educação e do espaço escolar, conforme mencionado anteriormente. Ela nasce impregnada pelo discurso ambientalista, com referências das ciências naturais e propensa a atividades vinculadas às áreas naturais protegidas voltadas à conservação ambiental e para a sensibilização em relação à natureza ainda numa ótica muito reducionista, apresentando fragilidades teórico-metodológicas. Essa perspectiva é visibilizada e mencionada por autores como Garcia-Gómez (2000), que afirma que, no princípio, a América Latina teve mais e melhores experiências em educação comunitária (não formal), enquanto que na Europa a EA se encontrava mais impregnada nos sistemas educativos, fortemente influenciada por movimentos docentes (educação formal).

Junto ao acúmulo da discussão sobre a própria identidade da EA, faz-se necessária a lapidação do que constitui o não formal da EA. Como afirma Quintas (2004), não basta também, aqui, dizer que galinha não é pato:

[...] é habitual se encontrar em documentos oficiais nacionais e internacionais, inclusive na Lei 9795/99, que dispõe sobre a Política Nacional de Educação Ambiental, a denominação de Educação Ambiental Não Formal para processos educativos praticados fora do currículo escolar. Definir galinha como a ave que não é pato não diz nada sobre ela. Pode-se saber tudo sobre patos, mas por esta definição continua-se não sabendo nada sobre galinhas. Do mesmo modo, pode-se conhecer bastante sobre Educação Ambiental Formal, mas continua-se ignorando o que qualifica a chamada Educação Ambiental Não Formal (QUINTAS, 2004, p.116).

O autor e educador do IBAMA faz essa ponderação para justificar a opção por definir a EA exercida no Instituto como um instrumento da gestão ambiental pública federal. Entendendo que negar o que um objeto é, nem sempre é a melhor maneira de caracterizá-lo, qualifica sua prática a partir do espaço em que ela se produz, o da gestão ambiental pública, por definição conflituoso. Enfatiza ainda o caráter político desta abordagem, que reside na intencionalidade que se coloca na ação educativa ao explicitar e colocar em diálogo as diferentes perspectivas de atores e fatores sociais que potencialmente envolvem riscos sócio ambientais e são geradores de conflitos. Elenca, ainda, os objetivos e os sujeitos prioritários da ação educativa (grupos vulneráveis):

[...] proporcionar condições para o desenvolvimento de capacidades (nas esferas dos conhecimentos, das habilidades e das atitudes) visando a intervenção individual e coletiva, de modo qualificado, tanto na gestão do uso dos recursos ambientais quanto na concepção e aplicação de decisões que afetam a qualidade do meio ambiente, seja ele físico-natural ou construído (QUINTAS, 2004, p. 115).

Nesse sentido, para enfrentar os problemas socioambientais é necessário fazer escolhas e tomar decisões. Enfatizando que, além de não serem técnicos, são eminentemente políticos. Tratando-se de uma questão de escolha, posicionamento frente às diversas questões de ordem coletiva e que dizem respeito a um bem comum.

Problematizando o que constitui a educação não formal, Gohn (2006) desenvolve um caminho que também pode nos ajudar na elaboração do nosso contexto. Diz a autora:

Articular a educação, em seu sentido mais amplo, com os processos de formação dos indivíduos como cidadãos, ou articular a escola com a comunidade educativa de um território é um sonho, uma utopia, mas também uma urgência e uma demanda da sociedade atual. Por isso trabalhamos com um conceito amplo de educação que envolve campos diferenciados [... ] a educação não-formal é aquela que se aprende 
"no mundo da vida", via os processos de compartilhamento de experiências, principalmente em espaços e ações coletivos cotidianos (GOHN, 2006, p.36).

Gonh $(2006,2014)$ aponta uma série de questões estruturantes para demarcar as diferenças que constituem o campo não formal da educação, além dos atributos que lhe são particulares como: não se organizar por séries, idade, conteúdos; atuar sobre aspectos subjetivos do grupo e trabalhar e formar a cultura política de um grupo. A despeito da terminologia utilizada, que ora parece indicar uma perspectiva tradicional de educação, os pressupostos que levanta podem nos ajudar a pensar na configuração dos espaços que poderiam estar contemplados no GDP em questão:

1. Quem é o educador? O grande educador é o outro, aquele com quem interagimos ou nos integramos.

2. Onde se educa? Os espaços educativos localizam-se em territórios que acompanham as trajetórias de vida dos grupos e indivíduos, fora das escolas, em locais informais, locais onde há processos interativos intencionais (a questão da intencionalidade é um elemento importante de diferenciação).

3. Como se educa? Em que situação, em qual contexto? Em ambientes e situações interativos, construídos coletivamente, segundo diretrizes de dados grupos, usualmente a participação dos indivíduos é optativa, mas ela também poderá ocorrer por forças de certas circunstâncias da vivência histórica de cada um. Há na educação não formal uma intencionalidade na ação, no ato de participar, de aprender e de transmitir ou trocar saberes.

4. Qual a finalidade ou objetivos? A educação não formal capacita os indivíduos a se tornarem cidadãos do mundo, no mundo. Sua finalidade é abrir janelas de conhecimento sobre o mundo que circunda os indivíduos e suas relações sociais. Seus objetivos não são dados a priori, eles se constroem no processo interativo, gerando um processo educativo. Um modo de educar surge como resultado do processo voltado para os interesses e as necessidades que dele participam. A construção de relações sociais baseadas em princípios de igualdade e justiça social, quando presentes num dado grupo social, fortalece o exercício da cidadania. A transmissão de informação e formação política e sociocultural é uma meta na educação não formal. Ela prepara os cidadãos, educa o ser humano para a civilidade, em oposição à barbárie, ao egoísmo, individualismo. Desenvolve laços de pertencimento. Ajuda na construção da identidade coletiva do grupo.

5. Os resultados esperados de sua ação é que desenvolva uma série de processos tais como: consciência e organização de como agir em grupos coletivos; construção e reconstrução de concepções de mundo e sobre o mundo; contribuição para um sentimento de identidade com uma dada comunidade; formar o indivíduo para a vida e suas adversidades (e não apenas capacitação para entrar no mercado de trabalho); quando presente em programas com crianças ou jovens adolescentes a educação não formal resgata o sentimento de valorização de si próprio, ou seja, dá condições aos indivíduos para desenvolverem sentimentos de autovalorização, de superação dos preconceitos que lhes são dirigidos, o desejo de lutarem para ser reconhecidos como iguais (enquanto seres humanos), dentro de suas diferenças (raciais, étnicas, religiosas, culturais etc.); os indivíduos adquirem conhecimento de sua própria prática, os indivíduos aprendem a ler e interpretar o mundo que os cerca (GOHN, 2006). 
Essas inquietações também são compartilhadas por Gadotti (2005, p.2), quando afirma que "usualmente define-se a educação não formal por uma ausência, em comparação com a escola, tomando a educação formal como único paradigma, como se a educação formal escolar também não pudesse aceitar a informalidade, o extraescolar", e continua "gostaria de definir a educação não formal por aquilo que ela é, pela sua especificidade e não por sua oposição à educação formal".

Essas referências nos parecem valiosas para orientar a constituição e a continuidade ou não do GDP Pesquisa em Educação Ambiental em Contextos não escolares, pois dá certo sentido (e pode implicar em algumas exigências) à heterogeneidade dos trabalhos e que pode configurar-se como o que está para além dos contextos não escolares. Elencam indicações estruturantes para a definição que buscamos, mas não são suficientes para resolver as dificuldades desse GDP com a quantidade e a qualidade dos trabalhos apresentados nos encontros bianuais.

\section{Considerações finais}

A própria heterogeneidade de situações em que se desenvolvem os trabalhos direcionados ao GDP em tela possibilita que grande parte dessas pesquisas se vincule, também, a outros GDPs como EA e Movimentos Sociais, EA e Culturas ou a EA e Políticas Públicas. Para as pesquisadoras e pesquisadores, dependendo da composição de cada GDP, a cada edição do evento, a participação em GDPs diferentes, com trabalhos do mesmo campo que o não escolar, pode se tornar mais produtiva. Uma orientação que, talvez, seja interessante, consistiria em definir e organizar os GDPs tendo por base a diversidade de espaços (tipos de contexto: UCs, museus e afins,) e sujeitos da ação educativa (movimentos sociais, grupos culturais, etnicorraciais etc.) como elementos estruturantes para seleção/composição do Grupo. Uma outra possibilidade seria promover momentos de junção e troca entre GDPs que apresentam forte interface, de modo a intensificar as trocas e os olhares sob óticas variáveis, numa perspectiva que favoreça o diálogo e enriqueça as experiências e as pesquisas desenvolvidas no campo da EA.

\section{Referências}

ALEGRÍA, P.A.H.; RODAS, J.A.; CÁCERES, M.A.M. Una propuesta de educación ambiental para una Microempresa Colombiana. In: ENCONTRO DE PESQUISA EM EDUCAÇÃO AMBIENTAL, 8, 2015, Rio de Janeiro. Anais...Rio de Janeiro: UNIRIO/UFRJ, 2015. p.01-16. Disponível em: <http://epea.tmp.br/epea2015_anais/pdfs/plenary/235.pdf>. Acesso em: 09 ago. 2016.

BRASIL. Ministério do Meio Ambiente. Secretaria de Articulação Institucional e Cidadania Ambiental. Departamento de Educação Ambiental. Os diferentes matizes da educação ambiental no Brasil: 1997-2007. Brasília: MMA, 2008. (Série Desafios da Educação Ambiental).

BRÜGGER, P. Educação ou adestramento ambiental? Santa Catarina: Letras contemporâneas, 1994.

CARVALHO, L.M. O discurso ambientalista e a Educação Ambiental: implicações para o ensino das ciências da natureza. In: SELLES, S.E.; CASSAB, M. (Orgs.). Currículo, docência e cultura. Niterói: Editora da UFF, 2012. v.1, p. 259-284.

ENCONTRO DE PESQUISA EM EDUCAÇÃO AMBIENTAL, 7, 2013. Rio Claro. Anais...Rio Claro: UNESP, 2013. Disponível em: 〈http://www.epea.tmp.br/epea2013_anais/welcome>. Acesso em: 18 jul. 2016. 
FOSSALUZA, A.S.; TOZONI-REIS, M.F.C. O financiamento das ONGs ambientalistas e sua influência nas ações em educação ambiental. In: ENCONTRO DE PESQUISA EM EDUCAÇÃO AMBIENTAL, 8, 2015, Rio de Janeiro. Anais...Rio de Janeiro: UNIRIO/UFRJ, 2015. p.01-15. Disponível em: <http://epea.tmp.br/epea2015_anais/pdfs/plenary/4.pdf〉. Acesso em: 09 ago. 2016.

GADOTTI, M. A questão da educação formal/não formal. In: SÉMINAIRE DE L'IDE - Droit à l'éducation: solution à tous les problèmes ou problème sans solution? 11, 2005, Sion. *Annales...* Genève: Institut International des Droits de L'enfant (IDE)/Institut Universitaire Kurt Bösch, 2005. p. $1-11$. Disponível

em: http://www.vdl.ufc.br/solar/aula_link/lquim/A_a_H/estrutura_pol_gest_educacional/aula_01/imagens/ 01/Educacao_Formal_Nao_Formal_2005.pdf

GARCIA-GÓMEZ, J. Modelo, realidad y posibilidades de la transversalidad: el caso de Valencia, España. Tópicos en Educación Ambiental, México, D.F., v.2, n.6, p. 53-62, Dez. 2000.

GOHN, M.G. Educação Não Formal, Aprendizagens e Saberes em Processos Participativos. Investigar em Educação - II ${ }^{a}$ Série, Porto, Portugal, n. 1, p. 35-50, 2014.

GOHN, M.G. Educação nãoformal, participação da sociedade civil e estruturas colegiadas nas escolas. Ensaio: aval. pol. públ. educ., Rio de Janeiro, v.14, n.50, p. 27-38, Jan./Mar. 2006.

HIGUCHI, M.I.G.; MAROTI, P.S. Espacialidades e socialidades da Educação Ambiental além dos muros da escola. Pesquisa em Educação Ambiental, Rio Claro, v. 9, n. 1, p. 95-109, Jan./Jun., 2014.

HIGUCHI, M.I.G.; ZATTONI, M.; BUENO, F.P. Educação Ambiental em contextos não escolares: definindo, problematizando e exemplificando. Pesquisa em Educação Ambiental, Rio Claro, v. 7, n. 2, p. 119-132, Jul./Dez., 2012.

JACOBUCCI, D.F.C. Contribuições dos espaços não formais de educação para a formação da cultura científica. Em extensão, Uberlândia, v.7, n.1, p. 55-66, 2008.

KUNIEDA, E. Espaços educadores no contexto do CESCAR (Coletivo Educador de São Carlos, Araraquara, Jaboticabal e Região/SP): do conceito à formação em educação ambiental. 2010. 145 f. Tese (Doutorado em Ciências, área de concentração em Ecologia e Recursos Naturais) - Centro de Ciências Biológicas e da Saúde, Universidade Federal de São Carlos, São Carlos, 2010.

LIERS, L.A.; PAIVA, C.F.E.; SILVA, R.L.F. A Educação Ambiental e a Gestão de Riscos GeológicoGeotécnicos análise de um recurso educativo. In: ENCONTRO DE PESQUISA EM EDUCAÇÃO AMBIENTAL, 8, 2015, Rio de Janeiro. Anais...Rio de Janeiro: UNIRIO/UFRJ, 2015. p.01-07. Disponível em: <http://epea.tmp.br/epea2015_anais/pdfs/plenary/226.pdf>. Acesso em: 09 ago. 2016.

MATAREZI, J. Estruturas e espaços educadores. In: FERRARO JÚNIOR, L. A. (Org.). Encontros e caminhos: formação de educadoras(es) ambientais e coletivos educadores. Brasília: MMA, Diretoria de Educação Ambiental, 2005. v. 1. p. 159-173.

OLIVEIRA, H.T. DI TULLIO, A.; FIGUEIREDO, A.N.; IARED, V.G.; MARTINS, C.; OLIVEIRA, S.M.; SANTOS, S.A.M.; THIEMANN, F.T.; VALENTI, M.W. (Orgs.) Educação Ambiental para a conservação da biodiversidade: animais de topo de cadeia. São Carlos: Diagrama Editorial, 2016.

ORJUELA, V.; MEJÍA, M.A. Diseño de una propuesta de educación ambiental a partir de la identificación de conflitos ambientales del corregimiento de Pance (Colombia). In: ENCONTRO DE PESQUISA EM EDUCAÇÃO AMBIENTAL, 8, 2015, Rio de Janeiro. Anais...Rio de Janeiro: UNIRIO/UFRJ, $2015 . \quad$ p.01-16. Disponível em: <http://epea.tmp.br/epea2015_anais/pdfs/plenary/187.pdf>. Acesso em: 09 ago. 2016. 
PEIXOTO, C.; MATTOS, U.A.O.; CATALDO, M. Contradições teórico-metodológicas do Projeto de Educação Ambiental dos Trabalhadores (PEAT), no âmbito do licenciamento ambiental para atividades de E\&P offshore. In: ENCONTRO DE PESQUISA EM EDUCAÇÃO AMBIENTAL, 8, 2015, Rio de Janeiro. Anais...Rio de Janeiro: UNIRIO/UFRJ, 2015. p.01-15. Disponível em: <http://epea.tmp.br/epea2015_anais/pdfs/plenary/215.pdf>. Acesso em: 09 ago. 2016.

PÉREZ, D.R.; MEINARDI, E. Educación Ambiental en viveros de restauración ecológica de zonas áridas de la Patagonia Argentina. In: ENCONTRO DE PESQUISA EM EDUCAÇÃO AMBIENTAL, 8, 2015, Rio de Janeiro. Anais...Rio de Janeiro: UNIRIO/UFRJ, 2015. p.01-15. Disponível em: <http://epea.tmp.br/epea2015_anais/pdfs/plenary/215.pdf>. Acesso em: 09 ago. 2016.

QUEIROZ, A.P.B. Educação Ambiental associada a Programa de Coleta Seletiva: realidade ou desafio? Estudo de caso do município de Niterói/RJ. In: ENCONTRO DE PESQUISA EM EDUCAÇÃO AMBIENTAL, 8, 2015, Rio de Janeiro. Anais...Rio de Janeiro: UNIRIO/UFRJ, 2015. p.01-15. Disponível em: <http://epea.tmp.br/epea2015_anais/pdfs/plenary/197.pdf>. Acesso em: 09 ago. 2016.

QUINTAS. J.S. Educação no processo de Gestão Ambiental: uma proposta de educação ambiental transformadora e emancipatória. In: LAYRARGUES, P.P. (Coord.). Identidades da educação ambiental brasileira. Brasília: Ministério do Meio Ambiente, 2004. p. 113-140. 